\title{
Graded Anderson procedure for correcting abnormal head posture in infantile nystagmus
}

\author{
Claudia Yahalom ${ }^{1} \cdot$ Karen Hendler $^{1} \cdot$ Pablo Galarza $^{1} \cdot$ Gad Dotan $^{2,3}$
}

Received: 25 April 2018 / Revised: 20 December 2018 / Accepted: 8 February 2019 / Published online: 25 March 2019

(c) The Royal College of Ophthalmologists 2019

\begin{abstract}
Purpose To describe the long-term results of Anderson procedure, which includes recession of the two extraocular yoke muscles responsible for eccentric eye position and abnormal head posture (AHP) in patients with infantile nystagmus.

Methods Retrospective data collection of patients who underwent an Anderson procedure at a single medical center by one surgeon from 2008 to 2016. The main outcome measure was the elimination of AHP following surgery.

Results Twenty-seven patients (18 males, 9 females) underwent an Anderson procedure during the study period. The average age at surgery was $8.6 \pm 7.7$ years and mean follow-up was $3.5 \pm 2.4$ years (range, 6 months-9 years). Before surgery all patients had AHP (17 left and 10 right head turns) greater than $25^{\circ}$ (mean $40.1 \pm 6.7^{\circ}$ ) that decreased significantly following surgery (mean 7.2 $\pm 7.6^{\circ}, P<0.001$ ). Surgery resulted in complete elimination of AHP in $14(52 \%)$ patients. In 10 (37\%) patients the residual head turn was $15^{\circ}$ or lower, and in only $3(8 \%)$ the post-operative AHP was $25^{\circ}$ or larger, requiring further surgery. It is important to note that none of the patients developed strabismus or duction limitation following surgery.

Conclusions Long-term results following the Anderson procedure show a stable decrease in AHP in patients with infantile nystagmus, often resulting in complete restoration of normal head posture. Involved risks of strabismus and limitation of ocular motility appear to be low.
\end{abstract}

\section{Introduction}

Infantile nystagmus is characterized by eye oscillations that are usually horizontal and typically increased by fixation and dampened by convergence [1]. There is often an eccentric gaze position in which the nystagmus is significantly reduced (null zone) and vision is maximally improved, typically resulting in adoption of abnormal head posture (AHP) intended to maintain the eyes in this preferred position. Consequently, a prolonged AHP may have associated implications, including skeletal deformities in the cervical spine, postural dysfunction, and impaired movement pattern, that often require surgical correction [2]. In

Claudia Yahalom

kloudia@hadassah.org.il

1 Ophthalmology Department, Hadassah-Hebrew University Medical Center, Jerusalem, Israel

2 Schneider Children's Medical Center of Israel, Petah Tikva, Israel

3 Sackler Faculty of Medicine, Tel Aviv University, Tel Aviv, Israel addition, AHP is an unnatural head position that may interfere with social interactions, eye to eye personal contact, and quality of life.

Various extraocular muscle surgeries [3-5] have been performed in an attempt to eliminate AHP in infantile nystagmus with eccentric null zone, but the Kestenbaum procedure as modified by Parks is probably the most commonly performed surgery [6]. The long-term results of this surgery were variable, as many patients readopted AHP after surgery. To enhance the effect and reduce the recurrence of AHP, modification or augmentations of Parks' dosage were reported by many authors [7-12]. Even with these modifications or augmentations, high rates of recurrence and undercorrection of head turns were previously reported. In addition, larger augmented surgery resulted in possible motility limitations or secondary misalignment after operation [13].

Von Noorden et al. [14] and Arroyo-Yllanes et al. [15] have revived interest in the Anderson operation for AHP in which only two muscles are recessed. However, reports on the results of this procedure are limited.

The purpose of this study was to evaluate the results of the Anderson procedure for correcting AHP in patients with 
infantile nystagmus performed with graded yoke muscle recessions instead of the previously described fixed amount of recessions $[14,15]$.

\section{Subject and methods}

We retrospectively reviewed the charts of consecutive patients with infantile nystagmus who underwent graded Anderson procedure between 2008 and 2016 at our Medical Center (Table 1). All patients were examined and operated by one surgeon (CY) and were followed through our low vision center. This center is based on a comprehensive approach including an extensive examination by an ophthalmologist, a genetic counsellor, optometrists, and a social worker, all of them specialized in low vision. This study was approved by the Institutional Review Board at Hadassah-Hebrew University Medical Center and was conducted in accordance with the rules of the Helsinki committee.

The indication for surgery in all patients was presence of AHP of at least $25^{\circ}$ that was verified at least twice in two separate visits to corroborate the angle and stability of AHP. Careful and prolonged examination (ranging from 20 to 30 min) were performed as part of a "low vision evaluation" and helped to rule out the possibility of periodic alternating

Table 1 Clinical characteristics of studied patients

\begin{tabular}{|c|c|c|c|c|c|c|c|c|c|}
\hline \multirow[t]{2}{*}{ No. } & \multirow[t]{2}{*}{ Ocular diagnosis } & \multirow{2}{*}{$\begin{array}{l}\text { Age at } \\
\text { surgery }\end{array}$} & \multirow[t]{2}{*}{ Gender } & \multicolumn{2}{|l|}{ Pre-op } & \multicolumn{3}{|l|}{ Post-op } & \multirow{2}{*}{$\begin{array}{l}\text { Follow-up } \\
\text { (years) }\end{array}$} \\
\hline & & & & Head turn & VA LogMAR & 1 Month & Last visit & $\begin{array}{l}\text { VA Log } \\
\text { Mar }\end{array}$ & \\
\hline 1 & OCA & 3.5 & M & LFT/RG 45 & 0.5 & RG 10 & RG 10 & 0.2 & 1 \\
\hline 2 & OCA & 18 & M & LFT/RG 40 & 0.8 & 0 & 0 & 0.8 & 1.5 \\
\hline 3 & IN & 9 & $\mathrm{~F}$ & RFT/LG 35 & 0.4 & 0 & 0 & 0.4 & 7 \\
\hline 4 & IN & 7 & M & RFT/LG 45 & 0.3 & LG 10 & LG 10 & 0.3 & 0.5 \\
\hline 5 & IN & 7 & $\mathrm{~F}$ & LFT/RG 40 & 0.1 & RG 10 & RG 10 & 0.1 & 4 \\
\hline 6 & IN & 8 & M & LFT/RG 40 & 0.5 & RG 10 & RG 10 & 0.3 & 2.5 \\
\hline 7 & Cong Cat & 7 & F & LFT/RG 40 & 0.5 & 0 & 0 & 0.4 & 3 \\
\hline 8 & IN & 5 & M & RFT/LG 25 & 0.5 & 0 & PAN 10 & 0.5 & 7 \\
\hline 9 & IN & 2.5 & $\mathrm{~F}$ & LFT/RG 25 & 0.8 & RG 25 & RG 25 & 0.8 & 6.5 \\
\hline 10 & IN & 9 & M & LFT/RG 45 & 0.5 & RG 25 & RG 25 & 0.5 & 3 \\
\hline 11 & IN & 15 & M & LFT/RG 30 & 0.5 & 0 & 0 & 0.4 & 2.5 \\
\hline 12 & IN & 12 & M & RFT/LG 40 & 0.5 & LG 10 & LG 10 & 0.5 & 6 \\
\hline 13 & Ret Dyst & 7 & M & RFT/LG 40 & 0.4 & 0 & 0 & 0.3 & 5 \\
\hline 14 & IN & 6 & M & RFT/LG 30 & 0.8 & 0 & 0 & 0.6 & 4.5 \\
\hline 15 & OCA & 4 & F & LFT/RG 35 & 0.5 & 0 & 0 & 0.3 & 9 \\
\hline 16 & OCA & 6 & F & RFT/LG 35 & 1 & 0 & PAN 10 & 1 & 4 \\
\hline 17 & OCA & 40 & M & LFT/RG 50 & 1.5 & RG 15 & RG 15 & 1.5 & 4 \\
\hline 18 & OCA & 3 & M & LFT/RG 45 & CSM & 0 & $\begin{array}{l}\text { Chin-down } \\
10\end{array}$ & 0.5 & 2 \\
\hline 19 & OCA & 5 & M & LFT/RG 40 & 0.6 & 0 & 0 & 0.5 & 2 \\
\hline 20 & OCA & 5 & M & LFT/RG 50 & 0.6 & RG 10 & RG 10 & 0.5 & 1.1 \\
\hline 21 & IN & 2 & $\mathrm{~F}$ & RFT/LG 40 & CSM & LG 15 & LG 15 & 0.7 & 1 \\
\hline 22 & Ret Dyst & 4 & M & LFT/RG 25 & 1.2 & 0 & 0 & 1.0 & 3.5 \\
\hline 23 & IN & 5 & M & RFT/LG 40/tilt ${ }^{\mathrm{a}}$ & 0.3 & Tilt L & Tilt L & 0.1 & 5.5 \\
\hline 24 & IN & 18 & M & LFT/RG 35/tilt ${ }^{\mathrm{a}}$ & 0.3 & Tilt R & Tilt R & 0.3 & 7 \\
\hline 25 & OCA & 8 & $\mathrm{~F}$ & RFT/LG 50/tilt ${ }^{\mathrm{a}}$ & 0.8 & LG 10 & LG $10+$ tilt & 0.8 & 3 \\
\hline 26 & IN & 13 & M & $\begin{array}{l}\text { LFT/RG 50/chin- } \\
\text { up }^{\text {a }}\end{array}$ & 0.0 & Chin-up & Chin-up & 0.0 & 2 \\
\hline 27 & IN & 5 & M & LFT/RG 50/tilt ${ }^{\mathrm{a}}$ & 0.2 & RG $10+$ tilt & RG $10+$ tilt & 0.2 & 1 \\
\hline
\end{tabular}

No. patient number, $A H P$ abnormal head posture, $O C A$ oculocutaneous albinism, $C P$ cerebral palsy, IN infantile nystagmus, $C O N G C A T$ congenital cataract, $P A N$ periodic alternating nystagmus, CSM central steady maintain, Ret Dyst retinal dystrophy, $L F T / R G$ left face turn/right gaze, $R F T / L G$ right face turn/left gaze

${ }^{\mathrm{a}}$ Multiplanar AHP pre-operative 
Table 2 Kestenbaun procedure modified by Parks

\begin{tabular}{llllll}
\hline & Degrees of LG AHP & LE recess LR & LE resect MR & RE recess MR & RE resect LR \\
\hline Classic Parks & 20 or less & 7 & 6 & 5 & 8 \\
Classic Parks & 30 & 9 & 8 & 6.5 & 10 \\
$+40 \%$ & 45 & 10 & 8.5 & 7 & 11 \\
$+60 \%$ & 50 & 11 & 9.5 & 8 & 12.5 \\
\hline
\end{tabular}

nystagmus (PAN). Eye movement recordings was not routinely performed in our clinic for evaluating nystagmus and therefore was not taken into consideration for choosing the type of AHP surgery to be done. All surgical decisions were based in clinical examination of the head posture. The amount of recession performed was determined according to the angle of head turn (based on Parks table for Kestenbaum procedure disregarding the resection component) (Table 2). In cases where there was an associated strabismus (without previous eye muscle operation performed), adjustments were made to surgical doses to address the deviation during the same surgery. Exclusion criteria included history of previous eye muscle surgery, incomplete data, or less than 6 months of follow-up.

Data were retrieved from the most recent examination before surgery up to the last available follow-up visit and included age when surgery was performed, gender, best corrected binocular visual acuity with preferred head posture, associated ocular pathology, strabismus measurements (if present), AHP angle, and yoke muscle recession performed. Most of the patients in our clinic have nystagmus and they all undergo a thorough slit lamp and fundoscopic examination in order to rule out common causes for nystagmus in our population as oculocutaneous albinism (OCA) and retinal dystrophies. Ocular coherence tomography was obtained in a few patients only (due to lack of cooperation during the test in children or nystagmus severity interfering with test performance).

OCA is a frequent cause of nystagmus among our patients, and hence, attempts were made by the surgeon to rule out OCA as far as possible based on examination and investigations available. Electrophysiology was performed in patients without a clear cause for nystagmus and genetic counseling was offered to all patients. The diagnosis of Idiopathic Infantile Nystagmus was reached only after ruling out all other known ocular and neurologic pathology.

The direction and angle of AHP was measured in degrees with a protractor goniometer (by eyesfirst.eu) while the patient fixated on the smallest visible visual acuity target at a distance of $6 \mathrm{~m}$. In uncooperative or young children, the AHP was assessed with photographs taken while the child was trying to fixate on a distant visual target. Snellen VA was recorded at $6 \mathrm{~m}$ distance; in younger children Lea symbols were used when child was cooperative enough. In non-cooperative young kids visual fixation assessment was performed. Results were converted to logarithm Minimum
Angle of Resolution (logMAR) for statistical purposes. The post-operative results were evaluated at 1 week, 1 month, and every 6 months thereafter.

Statistical analysis was performed using Prism 7 (GraphPad Software Inc., San Diego, CA). A paired $t$-test was performed comparing the angle of AHP and visual acuity before and after surgery. Descriptive statistics are provided and all statistical tests performed were two-tailed at an alpha level of $5 \%$.

\section{Results}

Twenty-seven patients (19 males) with nystagmus and AHP were included in this study. Patients' clinical characteristics are shown in Table 1. Ocular diagnosis originating the nystagmus included idiopathic infantile nystagmus $(n=$ 15), OCA $(n=9)$, retinal dystrophy $(n=2)$, congenital cataract $(n=1)$. Twenty-two $(81 \%)$ patients had a purely horizontal head turn and five (19\%) had some degree of additional head tilt or chin elevation or depression. The degree of "secondary head deviation" was difficult to establish but in all cases was less significant than the primary horizontal AHP.

Five patients had an additional esotropia ranging from 15 to 25 prism diopters on top of the AHP (Table 3). Surgical numbers were adjusted according to the angle of deviation at surgeon's discretion (Table 3).

Mean age when surgery was performed was 8.6 years (range, 2-40 years) and mean follow-up was 3.5 \pm 2.4 (range, 6 months-9 years). Seventeen (63\%) patients had a left head turn and $10(37 \%)$ had a right head turn, with a mean angle of $40.2 \pm 6.7^{\circ}$ (range, $25-50^{\circ}$ ). The lateral rectus muscle ipsilateral to the AHP was recessed between 6.0 and $11.0 \mathrm{~mm}$ (mean $9.1 \pm 1.5 \mathrm{~mm}$ ), and the contralateral medial rectus muscle was recessed between 5.0 and $8.0 \mathrm{~mm}$ (mean $6.8 \pm$ $1.0 \mathrm{~mm}$ ). Following surgery there was a significant decrease in the angle of AHP (mean 7.2 $\pm 7.6^{\circ}, P<0.001$, paired $t$-test) and improvement is visual acuity from $0.56 \pm 0.11$ preoperatively to $0.49 \pm 0.11$ postoperatively $(P<0.001$, paired $t$ test). Surgery resulted in complete elimination of AHP in 14 $(52 \%)$ patients. Ten $(37 \%)$ patients had a residual AHP angle of $15^{\circ}$ or less and were content with their improvement; four from these patients had a large angle of AHP $\left(50^{\circ}\right)$. Only 3 $(8 \%)$ patients had a remaining $\mathrm{AHP} \geq 25^{\circ}$, requiring further surgery (patients 9,10 , and 17). It is important to note that 
Table 3 Patients clinical and surgical details

\begin{tabular}{|c|c|c|c|c|c|c|c|}
\hline No. & $\begin{array}{l}\text { Ocular } \\
\text { diagnosis }\end{array}$ & $\begin{array}{l}\text { Strabimus pre- } \\
\text { operatory }\end{array}$ & $\begin{array}{l}\text { Pre-op head } \\
\text { turn }\end{array}$ & $\begin{array}{l}\text { MR } \\
\text { recess }\end{array}$ & LR recess & $\begin{array}{l}\text { Post-op head turn last } \\
\text { visit }\end{array}$ & Electrophisiology tests \\
\hline 1 & OCA & $\mathrm{N}$ & LFT/RG 45 & 7 & 9.5 & RG 10 & \\
\hline 2 & OCA & ET 20 PD & LFT/RG 40 & 7 & 8 & 0-Ortho & \\
\hline 3 & IN & ET 15 PD & RFT/LG 35 & 7 & 9 & 0-Ortho & \\
\hline 4 & IN & $\mathrm{N}$ & RFT/LG 45 & 7 & 10 & LG 10 & \\
\hline 5 & IN & ET 25 PD & LFT/RG 40 & 7 & 7 & $\begin{array}{l}\text { RG } 10+\text { residual ET } \\
10 \mathrm{PD}\end{array}$ & \\
\hline 6 & IN & $\mathrm{N}$ & LFT/RG 40 & 7 & 10 & RG 10 & \\
\hline 7 & Cong Cat & $\mathrm{N}$ & LFT/RG 40 & 8 & 10 & 0 & \\
\hline 8 & IN & ET 20 PD & RFT/LG 45 & 6 & 6 & PAN 10- Flick ET & VEP normal, ERG normal \\
\hline 9 & IN & ET 20 PD & LFT/RG 40 & 5.5 & 6.5 & RG 25- Flick ET & \\
\hline 10 & IN & $\mathrm{N}$ & LFT/RG 45 & 7 & 10 & RG 25 & \\
\hline 11 & IN & $\mathrm{N}$ & LFT/RG 30 & 6 & 8 & 0 & \\
\hline 12 & IN & $\mathrm{N}$ & RFT/LG 40 & 8 & 10 & LG 10 & \\
\hline 13 & Ret Dyst & $\mathrm{N}$ & RFT/LG 40 & 7.5 & 10.5 & 0 & $\begin{array}{l}\text { ERG: reduced mixed retinal } \\
\text { function }\end{array}$ \\
\hline 14 & IN & $\mathrm{N}$ & RFT/LG 30 & 5 & 6 & 0 & \\
\hline 15 & OCA & $\mathrm{N}$ & LFT/RG 35 & 6 & 8 & 0 & \\
\hline 16 & OCA & $\mathrm{N}$ & RFT/LG 35 & 6 & $6.5^{\mathrm{a}}$ & PAN 10 & \\
\hline 17 & IN & $\mathrm{N}$ & $\mathrm{RFT} / \mathrm{LG} 40^{\mathrm{b}}$ & 7 & 10 & Marked Tilt L & VEP normal, ERG normal \\
\hline 18 & IN & $\mathrm{N}$ & $\begin{array}{l}\text { LFT/RG 35/tilt } \\
\mathrm{R}^{\mathrm{b}}\end{array}$ & 6 & 8.5 & Tilt R & \\
\hline 19 & OCA & $\mathrm{N}$ & LFT/RG 45 & 7 & 10 & Chin-down 10 & \\
\hline 20 & OCA & $\mathrm{N}$ & $\begin{array}{l}\text { RFT/LG 50/ } \\
\text { tilt }^{\mathrm{b}}\end{array}$ & 8 & 11 & LG $10+$ tilt & \\
\hline 21 & OCA & $\mathrm{N}$ & LFT/RG 40 & 7 & 10 & 0 & \\
\hline 22 & OCA & $\mathrm{N}$ & LFT/RG 50 & 7 & 10 & RG 10 & \\
\hline 23 & IN & $\mathrm{N}$ & RFT/LG 40 & 7 & 10 & LG 15 & \\
\hline 24 & Ret Dyst & $\mathrm{N}$ & LFT/RG 35 & 5 & 7 & 0 & ERG: decreased cone function \\
\hline 25 & IN & $\mathrm{N}$ & $\begin{array}{l}\text { LFT/RG 50/ } \\
\text { chin-up }\end{array}$ & 7 & 10 & Chin-up & ERG normal,VEP normal \\
\hline 26 & OCA & $\mathrm{N}$ & LFT/RG 50 & 8 & 11 & RG 15 & ERG normal \\
\hline 27 & IN & $\mathrm{N}$ & $\begin{array}{l}\text { LFT/RG 50/ } \\
\text { tilt }^{\text {b }}\end{array}$ & 8 & 11 & RG $10+$ tilt & ERG normal, VEP normal \\
\hline
\end{tabular}

Above surgical numbers are based on surgeon's experience and discretion. They are not a surgical guide. No. patient number, $N$ no strabismus, $A H P$ abnormal head posture, $O C A$ oculocutaneous albinism, $C P$ cerebral palsy, IN infantile nystagmus, CONG CAT congenital cataract, $P A N$ periodic alternating nystagmus, $C S M$ central steady maintain, Ret Dyst retinal dystrophy, $L F T / R G$ left face turn/right gaze, $R F T / L G$ right face turn/ left gaz, 0 no AHP

${ }^{\mathrm{a} B o t h}$ eyes inferior oblique muscle recession added

${ }^{\mathrm{b}}$ Multiplanar AHP pre-operative

none of the patients developed strabismus or duction limitation following surgery. Two patients had features of PAN that developed years after surgery.

\section{Discussion}

In this study, we analyzed the largest case series published to date of patients undergoing the Anderson procedure for correcting AHP. Studied patients achieved a significant improvement in AHP and visual acuity following surgery, often resulting in complete elimination of the AHP. Manifest strabismus was successfully addressed as well in five patients by operating in same horizontal muscles. Most of our patients had a long follow-up period (mean 3 years) showing that the results achieved are usually stable over time.

The efficacy of the Anderson procedure has not been well studied. 
Von Noorden and Campos [14] described good results with this technique, but no published results are available. ArroyoYllanes et al. [15] described a "modified Anderson procedure" ( $2 \mathrm{~mm}$ retro-equatorial recession of yoke muscles) as effective in diminishing the AHP in all three axes, when the horizontal turn predominates over the torsional and vertical component. This same author reported that the large recessions they performed led to an overcorrection of horizontal head posture in $23.8 \%$ of their cases as well as duction deficit.

Gupta et al. [16] described 12 patients with infantile nystagmus that improved their face turn significantly following an augmented Anderson procedure using a 9- and $12-\mathrm{mm}$ recession of the yoke medial and lateral rectus muscles, respectively. Their follow-up time was very short (3 months post-operative only) compared to our long follow-up. Bishop described another four cases of a combined Anderson procedure with tenotomies (four eye muscles surgeries) with good results [17].

In our study we used a graded dose of yoke muscle recession that was adapted according to the severity of AHP, allowing for conservation of full horizontal eye movements; no patients showed limitations of ductions or overcorrections, which were previously described following larger amounts of muscle recessions $[15,16]$.

Most of our patients had a significant improvement in their AHP following surgery (89\%). Only three patients (11\%) needed a second surgery for residual significant head posture. We did not found any factor associated with failure of surgery in these cases.

Most of our patients with a multiplanar AHP (the horizontal turn predominating over the torsional and vertical component) showed improvement in all three axes following Anderson procedure, confirming previous observations. It is not clear why surgery on the horizontal muscles alone improves the torsional and/or vertical components of abnormal head positions. Arroyo-Yllanes have proposed that the blockage area is so far from the primary position that the vertical and torsional effects of cyclovertical muscles are exaggerated. With surgery on the horizontal muscles, the blockage point is moved to the primary position decreasing cyclovertical actions [15]. PAN following surgery appeared in the late follow-up of two patients. This secondary PAN to the best of our knowledge has not been previously described; it might be related to our long follow-up suggesting the high rate of time-related changes in null points over several years. Following surgery, binocular visual acuity significantly improved in primary position in our patients. This is a well-known positive effect of eye muscle surgery on patients with nystagmus resulting in dampening of nystagmus and improvement of visual function following the surgery [1, 16]. The most common ocular diagnosis was idiopathic infantile nystagmus. There was no correlation between the ocular diagnosis with the success of the surgical procedure. Two patients with retinal dystrophies had complete resolution of AHP following the Anderson procedure. Surgery in patient number 24 included recessions of 5 and 7 $\mathrm{mm}$ for MR and LR, respectively, demonstrating that relatively small doses may still improve AHP in some patients. The highest success rate was seen in patients with AHP up to $45^{\circ}$ and we think those patients might be the best suitable patients for this two muscle surgery.

Limitations of our work include the retrospective nature of the study and the relatively small size of studied population. Future plans include a carefully planned prospective study with more extensive records of pre-and post-operative parameters in order to learn more about this procedure.

In conclusion, we found that the Anderson procedure is an efficient technique with a high success rate for correcting mild to moderate AHP in most patients with nystagmus, with stable results over time. The graded dose of yoke muscle recession seems to add value to this technique avoiding overcorrections and limitations of ductions. The major advantages of this operation include shortening of the surgical time and sparing two horizontal rectus muscles in case further surgery is needed.

\section{Summary}

\section{What was known before}

- The most common surgical technique used till today for correcting head posture related to nystagmus has limited success rate and involves four rectus muscles.

\section{What this study adds}

- Anderson procedure is a successful technique for correcting head posture in patients with nystagmus. Surgical time shortening and sparing of two horizontal rectus muscles are among its major advantages along with stable long-term results.

\section{Compliance with ethical standards}

Conflict of interest The authors declare that they have no conflict of interest.

Publisher's note: Springer Nature remains neutral with regard to jurisdictional claims in published maps and institutional affiliations.

\section{References}

1. Hertle RW, Anninger W, Yang D, Shatnawi R, Hill VM. Effects of extraocular muscle surgery on 15 patients with oculo-cutaneous 
albinism (OCA) and infantile nystagmus syndrome (INS). Am J Ophthalmol. 2004;138:978-87.

2. Suhr MC, Oledzka M. Considerations and intervention in congenital muscular torticollis. Curr Opin Pediatr. 2015;27:75-81.

3. Kestenbaum A. Une nouvelle opération du nystagmus. Bull Soc Ophtalmol Fr. 1953;6:599.

4. Anderson JR. Causes and treatment of congenital nystagmus. Br J Ophthalmol. 1953;37:267.

5. Goto N. A study of optic nystagmus by the electrooculogram. Acta Soc Ophthal Jpn. 1954;58:851.

6. Parks MM. Congenital nystagmus surgery. Am Orthopt J. 1973;23:35-9.

7. Calhoun JH, Harley RD. Surgery for abnormal head position in congenital nystagmus. Trans Am Ophthalmol Soc. 1973;71:70-87.

8. Scott WE \& Clarke WN, eds. Surgical treatment of congenital nystagmus St. Louis: C. V. Mosby; 1974.

9. Mitchell PR, Wheeler MB, Parks MM. Kestenbaum surgical procedure for torticollis secondary to congenital nystagmus. J Pediatr Ophthalmol Strabismus. 1987;24:87-92.

10. Nelson LB, Ervin-Mulvey LD, Calhoun JH, Harley RD, Keisler MS. Surgical management for abnormal head position in nystagmus: the augmented modified Kestenbaum procedure. Br J Ophthalmol. 1984;68:796-800.
11. Scott WE, Kraft SP. Surgical treatment of compensatory head position in congenital nystagmus. J Pediatr Ophthalmol Strabismus. 1984;21:85-95.

12. Lee IS, Lee JB, Kim HS, Lew H, Han SH. Modified Kestenbaum surgery for correction of abnormal head posture in infantile nystagmus: outcome in 63 patients with graded augmentation. Binocul Vis Strabismus Q Spring. 2000; 15:53-8.

13. Kang NY, Isenberg SJ. Kestenbaum procedure with posterior fixation suture for anomalous head posture in infantile nystagmus. Graefes Arch Clin Exp Ophthalmol. 2009;247:981-7.

14. Von Noorden GV \& Campos EC. Binocular vision and ocular motility (VI edition): theory and management of Strabismus. St Louis: Mosby; 2002. p. 523.

15. Arroyo-Yllanes ME, Fonte-Vazquez A, Perez-Perez JF. Br J Ophthalmol. 2002;86:267-9.

16. Gupta R, Sharma P, Menon V. A prospective clinical evaluation of augmented Anderson procedure for idiopathic infantile nystagmus. JAAPOS. 2006;10:312-7.

17. Bishop JE. A novel new [yet again] procedure for correction of compensatory head posture in infantile nystagmus; augmented anderson plus dell'osso-hertle. Binocul Vis Strabol Q Simms Romano. 2011;26:37-42. 